\title{
VITAMIN A DEFICIENCY MODIFY THE ANTIOXIDANT DEFENSES AND THE TRACE ELEMENTS LEVEL IN RAT LIVER
}

\author{
A. C. Anzulovich*, L. Oliveros*, D. Martinez*, M. Baucells**, \\ and M. S. Gimenez \\ *Facultad de Química, Bioquímica y Farmacia \\ Universidad Nacional de San Luis \\ Ejército de los Andes 954 \\ 5700 San Luis, Argentina \\ **Serveis Científico-Técnics \\ Universitat de Barcelona \\ Lluis Solé i Sabarís 1-3, 08028-Barcelona \\ Spain
}

Considering that mammalian liver plays a major role in long chain fatty acids and vitamin A metabolism, we investigated if nutritional vit A deficiency modify in liver the enzymatic defense system components and the concentration of some trace elements which have an important role in free radical protection. Two groups of femal Wistar rats at $21 \mathrm{~d}$ age were ramdomly weaned onto either a vit A deficient diet (-A group) or the same diet with vit A 4,000 IU/Kg diet (control group). They were fed for 12 weeks before sacrifice. Serum and liver Vit A concentrations were measured by HPLC. Livers were homogeinized and the spontaneous chemiluminiscence was determined by using a liquid scintillation counter in out-of-coincidence mode. The catalase (CAT), superoxide dismutase (SOD) and glutation peroxidase (GSH-Px) activities weremeasured. The accumulation of end product of lipid peroxidation was determined by measurement of thiobarbituric acid-reactive substances (TBARiS). The Se, $\mathrm{Zn}$ and $\mathrm{Cu}$ analysis was performed by Inductively Coupled Plasma Mass Spectrometry. Results wzre analized by Studentis test. In relation to the control group, -A group showed: very low levels of serum and liver vit A, which confirms the vit A deficiency; an increase in the liver chemiluminiscence and activities of CAT and GSH-Px (1.8(0.1 vs $2.9(0.2 \mathrm{U} / \mathrm{mg}$ protein and 0.09 (0.01 vs 0.15 ( 0.01 (mol.min/mg protein, respectively), suggesting a high amount of substrates for the enzymes; and a decrease in the (g/g liver of $\mathrm{Zn}, \mathrm{Cu}$ and $\mathrm{Se}$, indicating that vit A deficiency could interfere with the depots of those trace elements in the liver. In spite of SOD activity and level of TBARiS were not changed, the results show that vit A nutritional deficiency affects the liver antioxidative capacity. 